\title{
Keep Moving Forward: Health Informatics and Information Management beyond the COVID-19 Pandemic
}

\author{
Barbara L. Massoudi', Diana Sobolevskaia² \\ 1 Rollins School of Public Health, Emory University \\ 2 Georgia State University
}

\section{Summary}

Objectives: To identify gaps and challenges in health informatics and health information management during the COVID-19 pandemic. To describe solutions and offer recommendations that can address the identified gaps and challenges.

Methods: A literature review of relevant peer-reviewed and grey literature published from January 2020 to December 2020 was conducted to inform the paper.

Results: The literature revealed several themes regarding health information management and health informatics challenges and gaps: information systems and information technology infrastructure; data collection, quality, and standardization; and information governance and use. These challenges and gaps were often driven by public policy and funding constraints.

Conclusions: COVID-19 exposed complexities related to responding to a world-wide, fast moving, quickly spreading novel virus. Longstanding gaps and ongoing challenges in the local, national, and global health and public health information systems and data infrastructure must be addressed before we are faced with another global pandemic.

\section{Keywords}

Health information management; public health; information governance; health information system; informatics; SARSCOV-2; coronavirus; COVID-19

Yearb Med Inform 2021:75-83

http://dx.doi.org/10.1055/s-0041-1726499

\section{Introduction}

Coronavirus disease 2019 (COVID-19) was responsible for a global pandemic beginning in late 2019. The outbreak of COVID-19 began in Wuhan, China on December 31, 2019. COVID-19 rapidly spread across the world and on March 11, 2020 the World Health Organization (WHO) declared a global pandemic [1]. As of December 2020, more than 82 million cases of COVID-19 worldwide have been recorded, along with more than 1.8 million deaths [2].

As the number of infected patients and deaths continued to rise globally, clinicians, scientists, epidemiologists, informaticians, and researchers worldwide struggled to understand all facets of COVID-19. The quickly evolving and growing pandemic revealed and compounded existing problems in the US healthcare system as well as delivery systems worldwide [3]. For example, resource constraints (beds, staff, supplies) on hospitals and health systems became apparent as the number of COVID-19 cases surged. Hospitals and health systems had to quickly scale up their surge capacity $[4,5]$. The impacts of the unprecedented challenges of COVID-19 in low-income and developing countries were enormous $[6,7]$. In the US, data reflect underlying health and healthcare inequities and disparities, as well as ongoing data and information gaps and limitations. Along with the clinical and public health impacts and concerns of dealing with the pandemic, there has been a concurrent and underlying data and information crisis. Despite the large investment in health information technology (IT) over the past two decades [8], in the US, there was inadequate capacity to prepare for, respond to and mitigate this pandemic.

The pandemic created the need for unique case definitions and ICD codes for COVID-19, but it also exposed existing needs for more timely, robust, and actionable data that are not unique to COVID-19 but were exacerbated by the urgency of the pandemic. These data are needed to: describe and characterize the pandemic and its spread; track and monitor the capacity of healthcare settings and facilities; assess the natural history of the disease and outcomes of patients; and confirm the amount and availability of critical supplies and personal protective equipment at provider sites. Further, critical gaps emerged about the way data are collected, gathered, reported, shared, and analyzed [9]. This paper focuses on the health information management challenges elevated during COVID-19 which require resolution to help ensure a strategic, progressive, and comprehensive approach to respond to ongoing and future public health emergencies.

Due to this paper's focus on the data and information gaps and challenges experienced during the global COVID-19 pandemic, health information management and health informatics are being considered together. These two fields, while differing in origin, have undergone a convergent evolution in recent years, evolving to adapt to a similar environment, and now share many common foci [10]. For purposes of this paper, public health informatics is considered an important component of the broader field of health informatics [11, 12]. 
The main objectives of this survey are to:

- Identify gaps and challenges in health information management during the COVID-19 pandemic;

- Describe potential solutions that can help address the gaps and challenges;

- Provide recommendations for policy, investment, and research actions.

\section{Methods}

To inform the paper, the authors conducted a literature review of relevant peer reviewed and grey literature articles focusing on health information and COVID-19 broadly, published from January 2020 to December 2020 in PubMed. Health informatics and health information search terms included "information exchange", "information governance", "health information exchange", "health information systems", "health information management", "digital healthcare", "electronic surveillance data", "COVID-19", "electronic medical records", and "electronic health records". Searches for grey literature (i.e., evidence not published in commercial publications), including, but not limited to, government publications, conference papers, and white papers were conducted using Google. Articles for review were drawn from peer-reviewed journals, conference papers, research performed by independent research and academic institutions, and letters to the editor. Other public documents reviewed included blogs and opinion pieces in peer-reviewed journals as well as articles in news media. A snowball approach was taken to identify additional sources of information to ensure as wide a review as possible to identify relevant materials. This included looking at the papers cited by identified papers as well as reviewing any papers citing source documents. Efforts were undertaken to identify relevant resources to depict the international aspects of this paper's focus.

\section{Results}

The review of the literature identified many challenges, barriers, and areas for resolution in health information management. These include challenges in information systems and the technologies underlying them; barriers to the collection of complete and accurate information; and challenges related to data and information governance, information systems and technology. Given the magnitude and pace of the COVID-19 pandemic, there was a heightened awareness of the need for secure collection, transmission, exchange, maintenance, and analysis of public health data. Related to this is the need to urgently expand, enhance, and modernize current public health data collection and reporting and to advance interoperability of data flow between and among public health authorities (PHA) and clinical healthcare providers (HCPs) [13].

Broadly speaking, public health functions during a pandemic include early and rapid detection, modeling, and assessment of potential impact, and proactively planning a systematic and iterative response [14]. To fulfill these functions, PHAs must effectively carry out several activities including data collection and sharing; case identification and management; contact tracing; mapping; monitoring of cases and transmission; community risk sensitization and engagement; preventive education; and other timely preparedness and response activities [15]. However, just executing these actions is not sufficient to limit spread and mortality. The entire public health response needs to be coordinated and synergistic, built upon a robust health information system infrastructure where real-time data collection, reporting and analytics underlie every activity, and findings from contact tracing are analyzed along with transmission statistics and disease monitoring to assess the efficacy of mitigation strategies [16]. The COVID-19 pandemic has highlighted the urgency to ensure robust public health prevention, preparedness, and responsiveness within and across several jurisdictions, including at the community, local, state, national and international levels [17].

\subsection{Information Systems and Information Technology Infrastructure}

In the US, congressional hearings [18] identified information management challenges during COVID-19 including those related to case identification and reporting; syndromic surveillance; electronic laboratory reporting; and contact tracing. These challenges have further emphasized the need for a robust and interoperable public health data and information systems infrastructure $[19,20]$ with an updated focus on information management and real-time, technology-driven, surveillance and reporting to respond effectively to public health emergencies [21, 22].

Significant US Federal Government efforts, including the development and release of executive orders and a data driven framework for pandemic response, are underway and directed toward addressing some of these long-standing issues [23, 24]. Additionally, the US Centers for Disease Control and Prevention (CDC) continues to refine, update, and implement its Data Modernization Initiative through funding from the CARES Act [25].

CDC's Public Health Emergency Preparedness Capability 6, developed to provide a baseline for what PHAs need to do to be prepared for public health threats, is about information sharing [26, 27]. Industry analysts urged the development of a comprehensive pandemic preparedness strategy including data and analytics using health IT [27]. The lack of interoperability of systems and the inability to share data efficiently between organizations have been a major barrier during the pandemic.

In the US, prior public policy to promote use of health information technologies focused largely on adoption of technologies through incentives, without requiring widespread adoption and use of standards. PHAs and HCPs often do not use the same information systems, data formats, or even data standards, thus hindering interoperability. With COVID-19 specifically, there is a disconnect between the case definition used by PHAs to report cases and the format and standards used by electronic health record systems [28]. These issues existed long before COVID-19 [29], and they are not unique to the US.

To operationalize and improve preparedness, prevention, detection, and response to public health emergencies, there is a need for new data and approaches for public health programs, including those made possible by health IT and digital tools. For example, case identification, investigation, and manage- 
ment can be augmented by new data and new digital tools and approaches to better identify the sources of COVID-19 and help prevent additional outbreaks. An example includes the adoption and deployment of applications, such as electronic case reporting (eCR) [36], electronic test orders and results (ETOR) implementations [37], and expansion of the Fast Healthcare Interoperability Resources (FHIR) application programming interfaces (APIs) being used for case reporting from electronic health records (EHRs) to PHAs. eCR was implemented to reduce data collection and reporting burdens by automating what had been a manual process. US state and local health departments implemented a more detailed form of COVID-19 electronic laboratory reporting (CELR). COVID-19-specific federal guidance provided information on regulatory requirements for COVID-19 point-of-care and rapid testing, including specimen collection and guidance on reporting test results. Other significant considerations relate to how to develop the infrastructure and strategy to scale up and deploy innovations at the population level [38]. Additionally, there is a need to develop enhanced approaches to information management to improve reporting from multiple sources, ensuring its consistency, and share data internationally.

With advancements in health IT and third-party applications, tools, and approaches such as artificial intelligence and machine learning have been proposed [39]. Recommendations have included implementing more comprehensive COVID-19 surveillance systems; scaling up rapid reporting to PHAs from providers; and establishing a national infectious disease forecasting center $[40,41]$.

Globally, low- and middle-income countries struggled with how to manage the pandemic without patient EHRs [42, 43] and limited capacity to prevent, detect, and respond to disease outbreaks [44]. Other countries reported challenges regarding information management as well as with their governance approaches, system capacity, and use of digital technologies [45]. In other countries, health management information systems at the national level also often have gaps between those systems and the local source systems [46].
Worldwide, government policies have varied in terms of containing, suppressing, and mitigating COVID-19 [5, 47-49]. The emergency response process in Belgium was divided into four phases: information-evaluation-coordination-decision making at the regional level and the final decision making at the federal level [50]. South Korea's rapidly controlled transmission, while implementing less stringent national social distancing measures than other countries, led to substantial interest in their "test, trace, isolate" strategy [51]. Additionally, there is a need to address the infrastructure and data deficiencies and limitations that have surfaced during COVID-19 as well as insufficient preparedness and surveillance capabilities complicated by health inequalities and the spread of misinformation [52].

\subsection{Data Collection, Data Quality, and Standardization}

Public health functions and processes in the US are decentralized and rely on information collected by thousands of federal, state, local, tribal and territorial PHAs. Data are submitted from state and local PHAs to federal programs in many ways and through numerous systems. Thus, in the US there are differences in the data definitions contained in federal, state, and local-level data reporting requirements, and across the globe lack of data comparability contributed to the challenges. The need for quality data (complete, accurate, timely, useful, understandable) is a foundational principle of health information management and is essential for healthcare and PHAs. The impact of the COVID-19 crisis differs across countries, but also across regions and municipalities within countries, both in terms of declared cases and related deaths. The information management challenges it presented were recognized across the globe.

Differences in data related to case counts, COVID-19-attributable hospitalizations and deaths, and testing have hindered the ability to detect threats and to learn from the global experience [53]. Efforts are needed to ensure that documentation and data about COVID-19 are captured consistently and accurately.
One of the key needs with the emergence of a new disease is to develop new standard diagnostic codes for the disease and cause of death, codes for new laboratory tests, new treatments, and other procedures. This need for new diagnostic and procedure codes was reiterated and addressed by multiple organizations and agencies including the WHO [54] and the CDC [55]. The Current Procedural Terminology $(\mathrm{CPT} \circledast)$ procedure codes were revised by the American Medical Association [56] and Logical Observation Identifiers Names and Codes (LOINC $\AA$ ) codes for laboratory tests were revised as well [57]. Finally, the US Centers for Medicare and Medicaid Services issued new Official Guidelines for Coding and Reporting [55]. However, given the broad scale of the challenges around data collection and use for COVID-19, it is unlikely that the new COVID-19 codes alone will be able to fully address these problems.

The need to prioritize the creation of a national testing strategy along with logistical and laboratory certification barriers led to confusion and a reported lack of availability of certain laboratory testing [58]. This lack of laboratory-confirmed case data has also compromised the ability to make real-time policy decisions, allocate resources, and inform preparedness plans. The absence of timely information and data sharing has led to weak national and international coordination, affecting logistics in supply allocations, triage and testing, quarantine, and treatment options [15]. The need for timely and robust data is essential for public health functions including disease surveillance to inform operational requirements such as hospital capacity planning and resource management and for a broad range of research needs, including studies of virus mutations, patient risk factors, clinical outcomes, and drug trials [59].

Other activities include exploring how recent changes in the US regulatory environment (such as interoperability and increasing patients' access to their data) may benefit public health and address access timely, accurate, and actionable information flow from EHRs to PHAs. Additional efforts are needed to improve data collection and data flows between HCPs and PHAs using health IT, including EHRs [30], with the 
goal of seamless interoperability between providers and public health systems [31]. Although there has been steady growth in bidirectional information exchange between HCPs and PHAs, some PHAs are still unable to receive electronic messages from clinical entities [32, 33]. Areas of consideration for data collection looking forward include new clinical data sources such as pre-diagnosis signs and symptoms from EHRs; data from "non-traditional" sites of care (such as pop-up clinics and mobile testing sites); and earlier, more robust, consistent, near real-time syndromic surveillance capabilities [31, 34-35]. Additionally, as COVID-19 cases increased in the US, data were subject to time-consuming review before being made available. The HHS system that released data suffered from serious time lags $[58,60]$ and was limited in the information it provided, leading stakeholders to demand greater data transparency.

Many public health and governmental agencies continue to rely on manual processes to gather, structure, and submit data, resulting in incomplete and missing information and therefore loss of data integrity and an inability to predict and map infection surges [61]. Ongoing and renewed attention is needed to enhance the quality, timeliness, and completeness of government-produced health data, by strengthening existing and contemplating new information management practices [62]. With the reliance on university and non-profit data dashboards, COVID-19 also demonstrated the value of public-private sector collaborations to produce and disseminate near real time and comprehensive data.

Globally, reports indicated lack of standard procedures resulting in haphazard data collection, often lacking crucial information. Researchers in China identified similar challenges to those found in the US, including low efficiency of data collection, difficulty in guaranteeing data quality, low efficiency of data use, and lack of timely data sharing [63]. The pandemic demonstrated the limitations of the existing systems for epidemic surveillance and monitoring and exposed gaps in data collection during an emerging outbreak [53].

Even when data are available and able to be shared, data quality issues related to completeness, timeliness, and validity still limit the utility of the data [62]. The ability to manage the pandemic has been hindered by incompleteness and unavailability of critical data needed by health officials to count deaths, particularly of non-residents such as those in hospitals, prisons, or long-term care facilities [64].

There is a need to address vulnerable population and communities disproportionately impacted by the COVID-19 pandemic, including how COVID-19 relates to factors of age, race, ethnicity, disability, and sex. HCPs and PHAs also need to have a better understanding of how COVID-19 has disproportionately impacted various geographical areas, populations, and communities to increase the capability of PHAs and the healthcare system to develop appropriate responses. The absence of complete and timely data has hindered reaching this goal. In some instances, the lack of needed demographic information - race, ethnicity, telephone, occupation, and physical address - has hindered treatment and mitigation actions about potential exposure to COVID-19. Countries have documented that ethnicities, even when required to be reported, are often missing [65]. In the US, assessing whether there was a differential risk of contracting COVID-19 for people of color was nearly impossible because race and ethnicity information was not included in the CDC Persons Under Investigation COVID-19 case report forms $85 \%$ of the time [66]. Identified limitations included lack of standard race/ethnicity categories; variations in which racial/ethnic groups for which data are reported; and a high proportion of cases with unknown race/ ethnicity [67].

Contact tracing, which depends on identifying and locating infected people for interviewing, was hindered because demographic information was often not available or not willing to be shared by healthcare facilities [68]. Contact tracing and testing efforts have been compromised because basic demographic data elements including telephone numbers and addresses to identify and communicate with patients are not complete or are missing or inaccurate. In the US, the Council of State and Territorial Epidemiologists (CSTE) reported that approximately $80 \%$ of COVID- 19 test results were missing demographic information [69].
Challenges related to accurately identifying patients and matching patients to their information, data collection and reporting, data quality, information management, misinformation, and deliberately falsified disinformation, as well as limitations of the broad health information infrastructure have characterized the pandemic response $[70,71]$.

\subsection{Governance and Use of Data and Information}

Issues related to underfunding of and improvements desperately needed to the public health infrastructure in the US are not new $[72,73]$. In response to this need, recommendations for sustained funding for public health preparedness and response programs have grown during COVID-19. Funding efforts have sought resources to support core functions and capabilities of a robust public health data and information technology infrastructure; a well-trained and appropriately resourced public health workforce; modernized data and surveillance capacities and developing evidence-based mitigation and treatments [21, 74]. Chronic underfunding has plagued PHAs across many parts of the world, not only in the US [75]. Despite previous efforts, investment and international assistance for pandemic preparedness remain insufficient [53].

The development, deployment and use of health IT and digital tools (for data monitoring, reporting, and contact tracing) have raised questions about legal and regulatory issues, including privacy and security, and data use and re-use.

While contact tracing is a core public health function and has been used to control the spread of infectious diseases for decades, the more widespread use of digital tools, including smart phones, to potentially expand tracing capabilities raised privacy questions [76-78]. Some researchers have noted the usefulness of this data to public health and of data sharing across geographic borders [79]. Others have raised the need to assess the potential public health benefits of digital tools and health IT against the imperative to protect and maintain the privacy of patient health data [80-85]. 
In the US, there was an urgent and ongoing need to reduce confusion about the applicability of Health Insurance Portability and Accountability Act of 1996 (HIPAA) requirements during the COVID-19 pandemic. To address these issues, in the US, federal authorities provided explanations and issued formal guidance on how patient health information may be used and disclosed in response to the COVID-19 nationwide public health emergency, based on the HIPAA public health exception. And the US CDC confirmed that all aspects of COVID-19 case investigation and contact tracing must be voluntary, confidential, and culturally appropriate [86]. Public health responses need to ensure that key elements of privacy are not abused or disregarded during emergencies [77, 81].

Additionally, clinical data contained in EHRs that could be useful to better understand individual level risk and protective factors was often not available to public health, because healthcare facilities sought to meet the "minimum necessary" requirements of the HIPAA legislation [87]. Despite decades of education in the provider community, ongoing providers' lack of compliance with legal requirements for public health reporting beyond the pandemic is a much bigger issue [88].

Concerns and recommendations about the ethical use of patient data during COVID-19 arose globally. While research shows that mobile position data contact tracing is important for epidemic control if it conforms to relevant data privacy regulations [89-91], frequently digital contact tracing appeared to conflict with patient data privacy regulations. Efforts to assess the impact of digital technologies on COVID-19 detection, prevention and treatment have also revealed challenges regarding data privacy and data access. In response to these concerns, international organizations released guidance around the use of these approaches. The WHO issued "Ethical considerations to guide the use of digital proximity tracking technologies for COVID-19 contact tracing" [92]. The United Nations (UN) Personal Data Protection and Privacy Principles, the UN Secretary-General's policy brief on human rights and COVID-19, and relevant health and humanitarian standards, data collection, use and processing by the UN System Organizations
[93] all informed this new area of inquiry into privacy protection. Researchers in China identified similar challenges to those found in the US, including data privacy protection issues [63]. Some countries' solutions to these challenges used sophisticated technological approaches to preserve privacy while benefitting from mobile phone-based surveillance $[94,95]$.

Similar to digital contact tracing concerns, scientific, legal, ethical and privacy considerations have been raised in other areas during the pandemic including the development of vaccine passports and digital vaccination certificates [96]. Questions also arose regarding privacy, data access and sharing during telehealth and telemedicine visits [97].

\subsection{Summary of Health Information Management Challenges and Gaps}

The main gaps and challenges to an effective pandemic response related to health information management and health informatics are: (1) lack of standards for information exchange between providers and PHAs; (2) problems in data collection and data quality, especially in terms of completeness and timeliness; and (3) governance, public policies and regulations. The latter included both the lack of policies to facilitate efficient data sharing, contact tracing and data governance, and also included providers' concerns about privacy regulations that led to incomplete data sharing. Governance and public policy barriers related to chronic underfunding of the public health infrastructure, and lack of sufficient investments in resources (including trained personnel) and infrastructure. Lack of international coordination was also identified as a significant challenge. There are numerous overlapping and intertwined legal, ethical, scientific, technical, technological, health equity, and privacy dimensions affecting how health information was managed or mismanaged during the COVID-19 global pandemic. To operationalize many of the data and information systems' recommendations, other longstanding systemic issues in health information management will also require attention.

\subsection{Proposed Solutions and Recommendations}

Several solutions and recommendations that can be implemented to address needs emerging from the pandemic response related to the management of health information are listed here. While not the focus of this paper, it is important to acknowledge the public health workforce gaps and challenges, especially the need for training and skills in epidemiology, data science, and informatics. Public policies and investment strategies should consider the need for more robust public health workforce capability and capacity. Below are several recommendations for consideration by national and global public-sector agencies and private sector organizations.

- Establish and convene global collaborations to enhance ways to operationalize the need for multilateral responses to public health crises such as COVID-19, including global data sharing using reliable and comparable data [98]. Such engagements could consider various approaches to reduce fragmented efforts both globally and nationally $[99,100]$ and increase coordinated public health responses;

- Address the need for sustained funding and support for public health data and information systems technology as well as innovative digital tools;

- Identify lessons learned and leverage best practices gleaned from the COVID-19 pandemic to:

- Accelerate and enhance efforts to address ongoing global shortcomings of public health data and information systems;

- Initiate activities that support increasing adoption of consensus-based open-source health IT and data standards, such as FHIR, for public health emergency preparedness and response functions, including prediction and prevention; syndromic surveillance; electronic data collection and reporting; case identification and investigation; immunization administration and tracking; laboratory reporting; and collecting and reporting data for situational awareness; 
- Improve public health IT and data systems to help ensure the efficient and secure collection, transmission, exchange, maintenance, and analysis of the wide array and diverse data that are needed (such as case reporting, hospitalizations, and deaths, and data about testing, treatments, supplies, and vaccinations);

- Focus efforts to develop, implement and evaluate ways to support real time bidirectional exchange of data between HCPs and PHAs, especially during public health emergencies;

- Enhance health data collection and reporting practices and processes regarding demographic information for patient identification and matching;

- Advance interoperability of real-time and consistent data flow between and among PHAs and HCPs [101]

- Address current data infrastructure gaps to improve and increase consistency in data collection, storage, analysis, and dissemination;

- Explore ways to extend and enhance different data systems standards and interfaces and to enhance data interoperability, quality, and governance [100];

o Identify common data elements, including minimal or essential data elements, along with standards and implementation specifications to help improve the collection, analysis, interpretation, and reporting of data and information during a public health emergency;

- Identify and leverage global lessons learned from COVID-19 to implement strategies, public policies, practices, and processes to anticipate and mitigate future emergencies and threats :

- Review existing practices around privacy, confidentiality and security of healthcare and public health data to enhance data sharing and exchange during emergencies;

- Educate HCPs about the HIPAA public health exception, its application, and their duty to report notifiable conditions to their PHAs;

- Develop public policies to address the need for real time access, exchange, and use of public health data for case identification and tracking, contact tracing, and treatment, and for research, evaluation and analytics while ensuring data governance, quality, and oversight;

- Develop policies to address coordination and guidance at the global, national, and local levels;

- Develop strategies to improve the electronic exchange of health information between federal, state, local, territorial, and tribal PHAs and HCPs and facilities;

- Consider approaches for de-identification and/or anonymization solutions for the public health use case, especially during emergencies and global pandemics.

\section{Conclusion}

COVID-19 exposed the global complexities and challenges related to a world-wide, fast moving, quickly spreading novel virus. While effective testing and vaccination will likely bring COVID-19 under control before the end of 2021, there are many other infectious diseases that could pose a serious threat to human health, and for which many have no vaccine or effective medications [102]. Longstanding gaps and ongoing challenges in the local, national, and global health information systems and data infrastructure must be addressed before we are faced with another global health crisis. Enhanced interoperable healthcare and public health information systems, information management, and standardized data collection and reporting are essential components for ongoing healthcare and public health emergency preparedness and resilience.

\section{References}

1. Cucinotta D, Vanelli M. WHO Declares COVID-19 a Pandemic. Acta Biomed 2020 Mar 19;91(1):157-60.

2. COVID-19 Map - Johns Hopkins Coronavirus Resource Center [Internet]. Johns Hopkins Coronavirus Resource Center; 2021 [cited 2021 March 7]. Available from: https://coronavirus. jhu.edu/map.html
3. Melvin SC, Wiggins C, Burse N, Thompson E, Monger M. The Role of Public Health in COVID-19 Emergency Response Efforts from a Rural Health Perspective. Prev Chronic Dis 2020;17:200256.

4. World Health Organization. WHO Releases Guidelines to Help Countries Maintain Essential Health Services During the COVID-19 Pandemic. Geneva, Switzerland: World Health Organization; 2020. https://www.who.int/ news-room/detail/30-03-2020-who-releasesguidelines-to-help-countries-maintain-essentialhealth-services-during-the-covid-19-pandemic

5. World Health Organization. Policy Brief Strengthening the Health System Response to COVID-19: Recommendations for the WHO European Region. Geneva, Switzerland: World Health Organization; 2020. http://www.euro.who. int/_data/assets/pdf_file/0003/436350/strengthening-health-system-response-COVID-19. pdf?ua $=1$

6. Chowdhury AZ, Jomo KS. Responding to the COVID-19 Pandemic in Developing Countries: Lessons from Selected Countries of the Global South. Development (Rome) 2020 Nov 10:1-10.

7. Rasul G. A Framework for Improving Policy Priorities in Managing COVID-19 Challenges in Developing Countries. Front Public Health 2020 Oct 14;8:589681.

8. Reisman M. EHRs: The Challenge of Making Electronic Data Usable and Interoperable. P T 2017 Sep;42(9):572-5.

9. Shaywitz D. Learning From COVID-19: The Lessons for Real World Data - TimmermanReport.com [Internet]. Timmerman Report; 2020 [cited 2021 April 1]. Available from: https:// timmermanreport.com/2020/10/learning-fromcovid-19-the-lessons-for-real-world-data/

10. Gibson CJ, Dixon BE, Abrams K. Convergent evolution of health information management and health informatics: a perspective on the future of information professionals in health care. Appl Clin Inform 2015 Mar 18;6(1):163-84.

11. AMIA. The Science of Informatics [Internet]. [cited 2021 April 17]. Available from: https:// www.amia.org/about-amia/science-informatics

12. Hersh, W. A stimulus to define informatics and health information technology. BMC Med Inform Decis Mak 2009;9:24. https://doi. org/10.1186/1472-6947-9-24

13. Madhavan S, Bastarache L, Brown JS, Butte AJ, Dorr DA, Embi PJ, et al. Use of electronic health records to support a public health response to the COVID-19 pandemic in the United States: a perspective from 15 academic medical centers. J Am Med Inform Assoc 2021 Feb 15;28(2):393-401

14. Romanelli RJ, Azar KMJ, Sudat S, Hung D, Frosch DL, Pressman AR. Learning Health System in Crisis: Lessons From the COVID-19 Pandemic. Mayo Clin Proc Innov Qual Outcomes 2021 Feb;5(1):171-6. Epub 2020 Oct 29.

15. Lal A, Ashworth HC, Dada S, Hoemeke L, Tambo E. Optimizing Pandemic Preparedness and Response Through Health Information Systems: Lessons Learned From Ebola to COVID-19. Disaster Med Public Health Prep 2020 Oct 2:1-8. Epub ahead of print. 
16. OECD Policy Responses to Coronavirus (COVID-19) The territorial impact of COVID-19: Managing the crisis across levels of government [Internet]. 2020 [cited 2021 April 13]. Available from: https://www.oecd. org/coronavirus/policy-responses/the-territorialimpact-of-covid-19-managing-the-crisis-acrosslevels-of-government-d3e $314 \mathrm{e} 1 /$

17. National Governors Association and the Association of State and Territorial Health Officers. Roadmap to Recovery: A Public Health Guide for Governors [Internet]. 2020 [cited 2021 April 13]. Available from: https://www.nga.org/center/ publications/roadmap-to-recovery/

18. Data for Decision-Making: Responsible Management of Data During COVID-19 and Beyond, $116^{\text {th }}$ United States Congress; 2020. (Testimony of Janet Hamilton).

19. US Department of Health and Human Services, Assistant Secretary for Planning and Evaluation. Information for health: a strategy for building the national health information infrastructure. Published November 28, 2016 [cited 2021 April 14]. Available from: https://aspe.hhs.gov/report/ information-health-strategy-building-national-health-information-infrastructure

20. Hagan C, Holubowich E, Criss T. Driving Public Health in the Fast Lane. CSTE.org 2020. [cited 2021 April 1]. Available from: https://resources. cste.org/data-superhighway/mobile/index.html

21. Miri A, O'Neill D. Accelerating Data Infrastructure For COVID-19 Surveillance and Management $\mid$ Health Affairs Blog [Internet]. Healthaffairs.org. 2020 [cited 2021 April 1]. Available from: https://www.healthaffairs.org/ do/10.1377/hblog20200413.644614/full/

22. Sittig DF, Singh H. COVID-19 and the Need for a National Health Information Technology Infrastructure. JAMA 2020 Jun 16;323(23):2373-4.

23. Executive Order on Ensuring a Data-Driven Response to COVID-19 and Future High-Consequence Public Health Threats | The White House [Internet]. The White House. 2021 [cited 2021 April 1]. Available from: https://www. whitehouse.gov/briefing-room/presidential-actions/2021/01/21/executive-order-ensuring-adata-driven-response-to-covid-19-and-futurehigh-consequence-public-health-threats/

24. Executive Order on National Strategy for the COVID-19 Response and Pandemic Preparedness [Internet]. Whitehouse.gov. 2021 [cited 2021 April 1]. Available from: https://www. whitehouse.gov/wp-content/uploads/2021/01/ National-Strategy-for-the-COVID-19-Response-and-Pandemic-Preparedness.pdf

25. Coronavirus Aid, Relief, and Economic Security Act (CARES) Act PL 116-136. Washington, DC: Government Printing Office; 2020.

26. Phelan A, Katz R. Publications - Center for Global Health Science and Security [Internet]. Georgetown University Center for Global Health Science and Security. 2020 [cited 2021 April 1]. Available from: https://ghss.georgetown.edu/ work/publications/

27. Medeiros D, Chien M. Address COVID-19 Preparedness and Response in Your Public Health Data and Analytics Strategy [Internet]. Gartner; 2020 [cited 2021 April 1]. Available from: https:// www.gartner.com/en/documents/3982198/ address-covid-19-preparedness-and-responsein-your-publi

28. ONC Health IT Certification Program Overview. [Internet]. Healthit.gov; 2020 [cited 2021 April 13]. Available from: https://www.healthit.gov/ sites/default/files/PUBLICHealthITCertificationProgramOverview.pdf

29. State Public Health ASTHO [Internet]. Astho.org; 2021 [cited 2021 March 22]. Available from: https://www.astho.org/StatePublicHealth/Improving-Public-Health-Surveillance-Through-Interoperability-Data-Standards-Legislation/01-24-19/

30. Office of Public Health Scientific Services. Centers for Disease Control and Prevention. Public Health Surveillance: Preparing for the Future. Atlanta, GA: Centers for Disease Control and Prevention; September 2018.

31. Data Modernization Initiative $\mid \mathrm{CDC}$ [Internet]. cdc.gov; 2020 [cited 2021 March 22]. Available from: https://www.cdc.gov/surveillance/surveillance-data-strategies/dmi-investments.html

32. Holmgren AJ, Apathy NC, Adler-Milstein J. Barriers to hospital electronic public health reporting and implications for the COVID-19 pandemic. J Am Med Inform Assoc 2020 Aug 1;27(8):1306-9.

33. Holmgren AJ, Apathy NC, Adler-Milstein J. Barriers to hospital electronic public health reporting and implications for the COVID-19 pandemic: the authors' reply. J Am Med Inform Assoc 2020 Nov 1;27(11):1823-4.

34. CDC Data Modernization Initiative: A Roadmap of Activities and Expected Outcomes [Internet]. cdc.gov. 2021 [cited 2021 March 22]. Available from: https://www.cdc.gov/ surveillance/pdfs/318212-A_DMI_LogicModel_July23b-508.pdf

35. Pryor R, Atkinson C, Cooper K, Doll M, Godbout E, Stevens MP, et al. The electronic medical record and COVID-19: Is it up to the challenge? Am J Infect Control 2020 Aug;48(8):966-7. Epub 2020 May 12

36. Public Health Data Modernization: Listening Session on Real-World Testing of 21st Century Cures Act Requirements. [Internet]. Cdc.gov; 2020 [cited 2021 April 1]. Available from: https:// www.cdc.gov/surveillance/pdfs/20_319521-D_ DataMod-Initiative_901420.pdf

37. Electronic Test Orders and Results (ETOR): A fundamental capability for public health laboratories. [Internet]. Aphl.org; 2019 [cited 2021 April 13]. Available from: https://www. aphl.org/aboutAPHL/publications/Documents/ INFO-2019-May-ETOR-high-level.pdf

38. Dzau VJ, Balatbat C. Strategy, coordinated implementation, and sustainable financing needed for COVID-19 innovations. Lancet $2020 \mathrm{Nov}$ 7:396(10261):1469-71.

39. Hick JL, Biddinger PD. Novel Coronavirus and Old Lessons - Preparing the Health System for the Pandemic. N Engl J Med 2020 May 14;382(20):e55. Epub 2020 Mar 25.

40. Gottlieb S, Rivers C, McClellan M, Silvis L, Watson C. National coronavirus response: A road map to reopening. American Enterprise Institute. 2020. [cited 2021 April 1]. Available from: https://www.aei.org/research-products/report/national-coronavirus-response-a-road-map-to-reopening/

41. Allain-Duprést D, Chatry I, Kornprobst A, Michalun M. The territorial impact of COVID-19: Managing the crisis across levels of government [Internet]. Oecd.org; 2020 [cited 2021 April 1]. Available from: http://www.oecd.org/coronavirus/policy-responses/the-territorial-impact-ofcovid-19-managing-the-crisis-across-levels-ofgovernment-d3e314e1/

42. Sylvestre E, Thuny RM, Cecilia-Joseph E, Gueye P, Chabartier C, Brouste Y, et al. Health informatics support for outbreak management: How to respond without an electronic health record? J Am Med Inform Assoc 2020 Nov 1;27(11):1828-9.

43. Lloyd-Sherlock PG, Kalache A, McKee M, Derbyshire J, Geffen L, Casas FG. WHO must prioritise the needs of older people in its response to the COVID-19 pandemic. BMJ 2020 Mar 23;368:m1164. Erratum in: BMJ. 2020 Mar 31;368:m1285.

44. Kandel N, Chungong S, Omaar A, Xing J. Health security capacities in the context of COVID-19 outbreak: an analysis of International Health Regulations annual report data from 182 countries. Lancet. 2020 Mar 28;395(10229):1047-53. Epub 2020 Mar 18.

45. Shaw R, Kim YK, Hua J. Governance, technology and citizen behavior in pandemic: Lessons from COVID-19 in East Asia. Progress in Disaster Science 2020;6:100090.

46. Nyatema AS. Bridging the gap in the Health Management Information System in the context of a changing health sector. BMC Med Inform Decis Mak 2010;10(36).

47. Lee SM, Lee D. Lessons Learned from Battling COVID-19: The Korean Experience. Int J Environ Res Public Health 2020 Oct 16;17(20):7548.

48. Moatti JP. The French response to COVID-19: intrinsic difficulties at the interface of science, public health, and policy. Lancet Public Health 2020;5(5):e255.

49. Shokoohi M, Osooli M, Stranges S. COVID-19 Pandemic: What Can the West Learn from the East? Int J Health Policy Manag 2020 Oct 1;9(10):436-8.

50. He R, Zhang J, Mao Y, Degomme O, Zhang WH. Preparedness and Responses Faced during the COVID-19 Pandemic in Belgium: An Observational Study and Using the National Open Data. Int J Environ Res Public Health 2020 Oct 30;17(21):7985.

51. Dighe A, Cattarino L, Cuomo-Dannenburg G, Skarp J, Imai N, Bhatia S, et al. Response to COVID-19 in South Korea and implications for lifting stringent interventions. BMC Med 2020 Oct 9;18(1):321.

52. Brownson RC, Burke TA, Colditz GA, Samet JA. Reimagining Public Health in the Aftermath of a Pandemic. Am J Public Health 2020 Nov;110(11):1605-10. Epub 2020 Aug 20.

53. Bollyky T, Patrick S. The U.S. Must Learn From COVID-19 to Prevent the Next Disaster [Internet]. Council on Foreign Relations. 2020 [cited 2021 April 1]. Available from: https:// www.cfr.org/report/pandemic-preparedness-les- 
sons-COVID-19/

54. Emergency use ICD codes for COVID-19 disease outbreak [Internet]. Who.int; 2021 [cited 2021 April 16]. Available from: https://www.who. int/classifications/classification-of-diseases/ emergency-use-icd-codes-for-covid-19-diseaseoutbreak

55. New ICD Code for Coronavirus. [Internet]. Cdc.gov; 2020 [cited 2021 April 16]. Available from: https://www.cdc.gov/nchs/data/icd/ Announcement-New-ICD-code-for-coronavirus-3-18-2020.pdf

56. COVID-19 CPT coding and guidance [Internet]. American Medical Association; 2021 [cited 2021 April 16]. Available from: https://www.ama-assn. org/practice-management/cpt/covid-19-cpt-coding-and-guidance

57. Guidance for mapping to SARS-CoV-2 LOINC terms - LOINC [Internet]. LOINC; 2020 [cited 2021 April 16]. Available from: https://loinc.org/ sars-coronavirus-2/

58. Maxmen A. Why the United States is having a coronavirus data crisis [Internet]. Nature.com; 2020 [cited 2021 March 7]. Available from: https://www.nature.com/articles/d41586-02002478-Z

59. Peek N, Sujan M, Scott P. Digital health and care in pandemic times: impact of COVID-19. BMJ Health Care Inform 2020;27:e100166.

60. Lumpkin J, Wiesenthal A. A Digital Bridge To Real-Time COVID-19 Data | Health Affairs Blog [Internet]. Healthaffairs.org; 2020 [cited 2021 March 7]. Available from: https://www.healthaffairs.org/do/10.1377 hblog20200729.517619/full

61. Kozlakidis Z, Abduljawad J, Al Khathaami AM, Schaper L, Stelling J. Global health and data-driven policies for emergency responses to infectious disease outbreaks. Lancet Glob Health 2020 Nov;8(11):e1361-e1363. Epub 2020 Aug 10

62. Pyo S, Reggi L, Martin E. The Potential Role of Open Data In Mitigating The COVID-19 Pandemic: Challenges And Opportunities | Health Affairs Blog [Internet]. Healthaffairs. org; 2020 [cited 2021 March 7]. Available from: https://www.healthaffairs.org/do/10.1377/ hblog20201029.94898/full/

63. Wu J, Wang J, Nicholas S, Maitland E, Fan Q. Application of Big Data Technology for COVID-19 Prevention and Control in China: Lessons and Recommendations. J Med Internet Res 2020;22(10):e21980. Published 2020 Oct 9.

64. Davenport T, Godfrey A, Redmond T. 2021. To Fight Pandemics, We Need Better Data. [Internet]. MIT Sloan Management Review; 2021 [cited 2021 March 22]. Available from: https:// sloanreview.mit.edu/article/to-fight-pandemicswe-need-better-data/

65. Hannigan A, Villarroel N, Roura M, LeMaster J, Basogomba A, Bradley C, et al. Ethnicity recording in health and social care data collections in Ireland: where and how is it measured and what is it used for? Int J Equity Health 2019 Dec 31;19(1):2.

66. Schulte F. As Coronavirus Strikes, Crucial Data In Electronic Health Records Hard To Harvest [Internet]. Kaiser Health News. 2021 [cited 2021
March 22]. Available from: https://khn.org/news/ as-coronavirus-strikes-crucial-data-in-electronic-health-records-hard-to-harvest/

67. Artiga S, Corallo B, Pham O. Racial Disparities in COVID-19: Key Findings from Available Data and Analysis - Issue Brief [Internet]. KFF.org. 2020 [cited 2021 April 1]. Available from: https:// www.kff.org/report-section/racial-disparities-incovid-19-key-findings-from-available-data-andanalysis-issue-brief/

68. Mostashari M, McClellan M. Data interoperability and exchange to support COVID-19 containment. [Internet]. Durham, NC: Duke Margolis Center for Health Policy; 2020. Available from: https://healthpolicy.duke.edu/ publications/data-interoperability-and-exchange-support-covid-19-containment

69. Kliff S, Sanger-Katz M. Bottleneck for U.S. Coronavirus Response: The Fax Machine [Internet]. Nytimes.com. 2020 [cited 2021 April 1]. Available from: https://www.nytimes.com/2020/07/13/upshot/coronavirus-response-fax-machines.html

70. MoscovitchB, Halamka JD, Grannis S. Better patient identification could help fight the coronavirus. NPJ Digit Med 2020 Jun 1;3:83. eCollection 2020

71. Woloshin S, Patel N, Kesselheim AS. False Negative Tests for SARS-CoV-2 Infection - Challenges and Implications. N Engl J Med 2020 Aug 6;383(6):e38. Epub 2020 Jun 5.

72. Institute of Medicine. For the Public's Health: Investing in a Healthier Future. Washington, DC: The National Academies Press; 2021

73. DeSalvo KB, Wang YC, Harris A, Auerbach J, Koo D, O'Carroll P. Public Health 3.0: A Call to Action for Public Health to Meet the Challenges of the 21st Century. Prev Chronic Dis 2017 Sep 7;14:E78.

74. The Impact of Chronic Underfunding on America's Public Health System: Trends, Risks, and Recommendations [Internet]. Tfah.org; 2020 [cited 2021 April 1]. Available from: https:// www.tfah.org/report-details/publichealthfunding2020/

75. Renda, A, Castro, R. Toward stronger EU governance of health threats after the COVID-19 pandemic. Eur J Risk Regul 2020;1-10.

76. Anderson J, Rainie L. Concerns about democracy in the digital age [Internet]. Pew Research Center: Internet, Science \& Tech; 2020 [cited 2021 April 16]. Available from: https://www. pewresearch.org/internet/2020/02/21/concerns-about-democracy-in-the-digital-age/

77. Contact Tracing in the Context of COVID-19. World Health Organization. Who.int; 2020 [cited 2021 April 1]. Available from: https://www.who. int/publications/i/item/contact-tracing-in-thecontext-of-covid-19

78. Use of Surveillance to Fight Coronavirus Raises Concerns about Government Power after Pandemic Ends. [Internet]. 2020 [cited 2021 April 16]. Available from: https://www. cnbc.com/2020/03/27/coronavirus-surveillance-used-by-governments-to-fight-pandemic-privacy-concerns.html

79. Plasek JM, Tang C, Zhu Y, Huang Y, Bates DW. Following data as it crosses borders during the
COVID-19 pandemic. J Am Med Inform Assoc 2020;27(7):1139-41.

80. Howard N, Ermilio J. EHR Interoperability: Public Health Benefits \& Privacy Considerations [Internet]. 2020. [cited 2021 April 1]. Available from: https://www.covingtondigitalhealth.com/2020/07/ehr-interoperability-public-health-benefits-privacy-considerations/

81. Ekong I, Chukwu E, Chukwu M. COVID-19 Mobile Positioning Data Contact Tracing and Patient Privacy Regulations: Exploratory Search of Global Response Strategies and the Use of Digital Tools in Nigeria. JMIR Mhealth Uhealth 2020 Apr 27;8(4):e19139.

82. Braithwaite I, Callender T, Bullock M, Aldridge RW. Automated and partly automated contact tracing: a systematic review to inform the control of COVID-19. Lancet Digit Health 2020 Nov;2(11):e607-e621. Epub 2020 Aug 19

83. Jung G, Lee H, Kim A, Lee U. Too Much Information: Assessing Privacy Risks of Contact Trace Data Disclosure on People With COVID-19 in South Korea. Front Public Health 2020;8:305. Published 2020 Jun 18.

84. Gellman R, Dixon P. COVID-19 and HIPAA: HHS's Troubled Approach to Waiving Privacy and Security Rules for the Pandemic | World Privacy Forum [Internet]. Worldprivacyforum. org; 2020 [cited 2021 April 1]. Available from: https://www.worldprivacyforum.org/2020/09/ covid-19-and-hipaa/

85. Marquez B, Pascual N, Gaite D. Protecting patients' privacy in a pandemic: latest guidance from the Philippines | Lexology [Internet]. Lexology.com; 2020 [cited 2021 April 1]. Available from: https://www.lexology.com/ library/detail.aspx?g=f6dfc332-0e11-4010-aaf4$597919 b 86836$

86. Coronavirus (COVID-19) Frequently Asked Questions: Contact Tracing [Internet]. Centers for Disease Control and Prevention. 2021 [cited 2021 April 17]. Available from: https://www. cdc.gov/coronavirus/2019-ncov/faq.html?CDC_AA_refVal=https $\% 3 \mathrm{~A} \% 2 \mathrm{~F} \% 2 \mathrm{Fwww} . \mathrm{cdc}$. gov $\% 2$ Fcoronavirus $\% 2$ F 2019 -ncov $\% 2 F p h-$ p\%2Fcontact-tracing-faq.html\#Contact-Tracing

87. Biswas $\mathrm{S}$, Ghosh $\mathrm{P}$, Chakraborty D, Chatterjee A, Dutta S, Saha MK. COVID-19 Infection: Data Gaps for Diagnostic Laboratory Preparedness and Tasks on Hand. Viral Immunol 2020 Dec 1. Epub ahead of print.

88. Brissette I, Gelberg KH, Grey AJ. The effect of message type on physician compliance with disease reporting requirements. Public Health Rep 2006; 121(6):703-9.

89. Sookman B. AI And Contact Tracing: How to Protect Privacy While Fighting The COVID-19 Pandemic. [Internet]. 2020. Macdonaldlaurier. ca. Available at: https://macdonaldlaurier.ca/ files/pdf/20200416_COVID-Privacy_Sookman_COM

90. Ahmed K, Bukhari MA, Mlanda T, Kimenyi JP, Wallace P, Okot Lukoya C, et al. Novel Approach to Support Rapid Data Collection, Management, and Visualization During the COVID-19 Outbreak Response in the World Health Organization African Region: Development of a Data Summarization and Visualization Tool. JMIR Public 
Health Surveill 2020 Oct 14;6(4):e20355.

91. Kringos D, Carinci F, Barbazza E, Bos V, Gilmore K, Groene O, et al; HealthPros Network. Managing COVID-19 within and across health systems: why we need performance intelligence to coordinate a global response. Health Res Policy Syst 2020 Jul 14;18(1):80.

92. Ethical considerations to guide the use of digital proximity tracking technologies for COVID-19 contact tracing [Internet]. World Health Organization. Who.int; 2020 [cited 2021 April 1]. Available from: https://www.who.int/publications/i/ item/WHO-2019-nCoV-Ethics_Contact_tracing_apps-2020.1

93. COVID-19 and Human Rights: We are All in This Together [Internet]. United Nations Sustainable Development Group. Unsdg.un.org; 2020 [cited 2021 April 1]. Available from: https://unsdg. un.org/sites/default/files/2020-04/COVID-19and-Human-Rights.pdf

94. Whaiduzzaman M, Hossain MR, Shovon AR, Roy S, Laszka A, Buyya R, et al. A Privacy-Preserving Mobile and Fog Computing Framework to Trace and Prevent COVID-19 Community Transmission. IEEE J Biomed Health Inform 2020 Dec;24(12):3564-75. Epub 2020 Dec 4.

95. Kim W, Lee H, Chung YD. Safe contact tracing for COVID-19: A method without privacy breach using functional encryption techniques based-on spatio-temporal trajectory data. PLoS One 2020 Dec 11;15(12):e0242758.

96. Persad G, Emanuel EJ. The Ethics of COVID-19 Immunity-Based Licenses ("Immunity Passports"). JAMA 2020;323(22):2241-2.

97. Bassan S. Data privacy considerations for telehealth consumers amid COVID-19. J Law Biosci 2020;7(1):Isaa075.

98. LoTempio J, Spencer D, Yarvitz R, Delot Vilain A, Vilain E, Délot E. We Can Do Better: Lessons Learned on Data Sharing in COVID-19 Pandemic Can Inform Future Outbreak Preparedness and Response. Science \& Diplomacy 2020;9(2) [cited 2021 April 1]. Available from: https://www.sciencediplomacy.org/article/2020/ we-can-do-betterlessons-learned-data-sharingin-covid-19-pandemic-can-inform-future

99. Chin S, Chin C. To mitigate the costs of future pandemics, establish a common data space. [Internet]. Brookings; 2021 [cited 2021 March 22]. Available from: https://www.brookings.edu/blog/ techtank/2020/11/02/to-mitigate-the-costs-of-future-pandemics-establish-a-common-data-space/

100. Communication from the Commission to the European Parliament, the Council, the Euro- pean Economic and Social Committee and the Committee of the Regions. A European Strategy for Data; 2020. Available at: https://ec.europa. eu/info/sites/info/files/communication-european-strategy-data-19feb2020_en.pdf

101. McClellan M, Mostashari F, Barker T. Health care payment to support COVID-19 detection and containment [Internet]. Durham, NC: Duke Margolis Center for Health Policy; 2020. Available from: https://healthpolicy.duke.edu/ sites/default/files/2020-06/health_care_payment_to_support_covid-19_detection_and_containment_final.pdf

102. 10 infectious diseases that could be the next pandemic [Internet]. Gavi.org; 2020 [cited 2021 March 7]. Available from: https://www. gavi.org/vaccineswork/10-infectious-diseases-could-be-next-pandemic

\section{Correspondence to:}

Barbara L. Massoudi, MPH, PhD

Department of Biostatistics \& Bioinformatics

Rollins School of Public Health at Emory University

E-mail:bmassou@emory.edu 